\title{
The Role of Interneurons in Shaping Purkinje Cell Responses in the Cerebellar Cortex
}

\author{
Maria Johanna Dizon and Kamran Khodakhah \\ Dominick P. Purpura Department of Neuroscience, Albert Einstein College of Medicine, Bronx, New York 10461
}

The well established anatomy of the cerebellar cortex has led to suggestions that cerebellar molecular layer interneurons laterally inhibit Purkinje cells. In support of the anatomical predictions, on-beam excitation and off-beam inhibition of Purkinje cells have been shown to occur when the surface of the cerebellum is electrically excited. Patchy excitation of Purkinje cells with flanking inhibition of sagittally oriented Purkinje cells have also been demonstrated following peripheral stimulation in vivo. To extend these observations, we mapped the functional connectivity between granule cells, molecular layer interneurons, and Purkinje cells in rats. Patches of granule cells were asynchronously activated by photostimulation to mimic their excitation by a mossy fiber as it occurs in vivo. We found with remarkable consistency that, in the sagittal orientation, granule cells elicit a stereotypic set of responses. Granule cells immediately underneath a Purkinje cell provide pure excitation. Granule cells positioned $340-400 \mu \mathrm{m}$ laterally provided pure inhibition, consistent with the lateral inhibition proposed earlier. The net effect of exciting granule cells in between these two extremes was to provide a systematic change in the response of Purkinje cells, from net excitation to net inhibition moving laterally from the Purkinje cell. In contrast to the sagittal orientation, in the coronal orientation the organization of Purkinje cell responses with granule cell activation was remarkably different. Independent of the location of granule cells, within the $480 \mu \mathrm{m}$ lateral distance examined, molecular layer interneurons reduced the strength of granule cell inputs to Purkinje cells to a comparable extent.

\section{Introduction}

Purkinje cells are the main computational units of the cerebellum, each integrating a staggering 150,000 synaptic inputs on top of their spontaneous baseline firing rate, to generate the sole output of the cerebellar cortex (Napper and Harvey, 1988; Harvey and Napper, 1991; Raman and Bean, 1999). Purkinje cells exhibit firing rates that increase and decrease from their baseline intrinsic spontaneous rate in correlation with different aspects of movement (Thach, 1968, 1970). Dysfunction of Purkinje cells can lead to lack of motor coordination (ataxia), a characteristic symptom of many debilitating movement disorders (Ito, 1984). However, the details of how Purkinje cells process such a considerable number of inputs are not understood.

The simple, repeating cytoarchitecture of the cerebellar cortex has provided clues regarding information processing by the cerebellum. Some 50 years ago, on the basis of the anatomy, Szentagothai (1965) suggested that if basket cells were inhibitory then they would provide the substrate for lateral inhibition of Purkinje cells. This is because of the orthogonal arrangement of excitation and inhibition onto Purkinje cells: the axons of molecular layer

\footnotetext{
Received March 16, 2011; revised May 2, 2011; accepted May 27, 2011.

Author contributions: M.J.D. and K.K. designed research; M.J.D. performed research; M.J.D. and K.K. analyzed data; M.J.D. and K.K. wrote the paper.

This work was supported by National Institutes of Health under Grant NS050808 (K.K.) and Ruth L. Kirschstein National Research Service Award NS064778 (M.J.D.).

Correspondence should be addressed to Kamran Khodakhah, Dominick P. Purpura Department of Neuroscience, Albert Einstein College of Medicine, Rose F. Kennedy Center, Room 506, 1410 Pelham Parkway South, Bronx, NY 10461. E-mail: k.khodakhah@einstein.yu.edu.

DOI:10.1523/JNEUROSCI.1350-11.2011

Copyright $\odot 2011$ the authors $\quad 0270-6474 / 11 / 3110463-11 \$ 15.00 / 0$
}

interneurons (basket and stellate cells) run sagittally, while the axons of granule cells (parallel fibers) run coronally. The suggestion by Szentagothai motivated the beam hypothesis whereby a beam of parallel fibers activates a long row of Purkinje cells in the coronal orientation while inhibiting laterally positioned Purkinje cells (Andersen et al., 1964; Szentagothai, 1965; Eccles et al., 1967; Eccles, 1973; Palay and Chan-Palay, 1974). Imaging experiments in which the surface of the cerebellum was electrically stimulated supported this idea (Cohen and Yarom, 2000a,b; Sullivan et al., 2005; Gao et al., 2006), although these experiments suffer from the caveat that under physiological conditions mossy fibers activate patches of granule cells and not a beam of parallel fibers. Nonetheless, the initial concept of lateral inhibition remains a viable one since voltage-sensitive dye imaging has shown that activation of mossy fibers or peripheral stimulation can elicit such a pattern of activity (Cohen and Yarom, 1998; Gao et al., 2006).

Here, we sought to examine in detail the functional connectivity between granule cells, molecular layer interneurons, and Purkinje cells. Our approach was to map Purkinje cell responses to photostimulation of granule cell patches using noninvasive single-unit recording in cerebellar slices. Overall, we found that, in the sagittal orientation, Purkinje cells exhibit a stereotypic set of responses organized such that granule cells positioned medially underneath the Purkinje cell tended to be purely excitatory, whereas granule cells positioned more laterally mediated inhibition. Granule cells located in between elicited a gradation of responses from net excitatory to net inhibitory, moving laterally. In contrast, in the coronal orientation, granule cells adjacent to or as far away as $480 \mu \mathrm{m}$ lateral from the Purkinje cell comparably mediated inhibition. 


\section{Materials and Methods}

Preparation of slices. Juvenile (15-19 d postnatal) and adult (2-5 months postnatal) Wistar rats (The Jackson Laboratory) of either sex were anesthetized with halothane and decapitated, in accordance with the guidelines set by Albert Einstein College of Medicine. The brain was quickly removed and immersed in cold extracellular recording solution and the cerebellum isolated. Sagittal $(300 \mu \mathrm{m})$ or coronal $(400 \mu \mathrm{m})$ slices were cut from the vermis using a vibratome, allowed to recover in recording solution at $35^{\circ} \mathrm{C}(1 \mathrm{~h})$, and maintained at room temperature until use (1-4h).

Extracellular recording. Slices were mounted in a chamber on the stage of an upright Olympus BX61WI or Zeiss Axioskop with a $40 \times$ waterimmersion objective (numerical aperture, 0.8 ) and were superfused continuously at a rate of $1.5 \mathrm{ml} / \mathrm{min}$ with recording solution containing the following (in mM): $125 \mathrm{NaCl}, 2.5 \mathrm{KCl}, 26 \mathrm{NaHCO}_{3}, 1.25 \mathrm{NaH}_{2} \mathrm{PO}_{4}, 1$ $\mathrm{MgCl}_{2}, 2 \mathrm{CaCl}_{2}, 11$ glucose, pH 7.4 with $5 \% \mathrm{CO}_{2}-95 \% \mathrm{O}_{2}$, at $35 \pm 1^{\circ} \mathrm{C}$. Single-unit extracellular field potential recordings were made from individual Purkinje cells using a homemade differential amplifier. The tip of a glass pipette electrode (tip diameter, $\sim 1 \mu \mathrm{m}$ ) filled with recording solution was positioned near the Purkinje cell body at the axon hillock, where the largest voltage changes were usually recorded. Spontaneous action potentials were reported as negative deflections of $50-2500 \mu \mathrm{V}$. The target Purkinje cell was visualized on a gridded monitor, and its relative location, together with the orientations and extents of the surrounding cell layers, was noted before the experiment. More detailed two-dimensional schematics of the cell and surrounding cell layers were prepared following the experiment, making sure the slice did not drift. This included outlining the pia, Purkinje cell layer, granule cell layer, and white matter to show the orientation of the folium from which the Purkinje cell was recorded. These were reproduced digitally using a Wacom tablet and Adobe Illustrator.

Photolytic stimulation. Ultraviolet light from a continuous multiline krypton ion laser (I302C; Coherent) was used to photorelease glutamate from $250 \mu \mathrm{M}$ 4-methoxy-7-nitroindolinyl (MNI)-caged-L-glutamate (Tocris) that was preequilibrated with the slice. The light was launched through a fiber optic cable into the epifluorescence port of a Zeiss or Olympus microscope equipped with a set of lenses and dichroic mirror to focus the beam through a $40 \times$ water-immersion objective onto the surface of the specimen plane, and mirror galvanometers to steer it in the $x-y$ plane. The duration ( $1 \mathrm{~ms}$ pulse) and intensity of illumination was adjusted using an accousto-optical modulator (AOM 35085-3-350; NEOS). We have previously shown that photostimulation of granule cells in this manner asynchronously activates them, resulting in EPSCs in Purkinje cells that take $\sim 10 \mathrm{~ms}$ to peak and decay with a time constant of 20-30 ms (Walter and Khodakhah, 2006), very much analogous to that expected from the activity of granule cells in vivo following a discrete sensory stimulus (Jaeger and Bower, 1994). The laser intensity was adjusted so that a patch of granule cells positioned along the vertical axis of the Purkinje cell (i.e., medial to it) at least doubled the firing rate of the overlying Purkinje cell. A custom-written automated program was used to target and gate the beam at multiple preset sites along a rectangular array aligned with the slice, within either (1) a $13 \times 9$ array spanning $520 \times 360 \mu \mathrm{m}$ (40 $\mu \mathrm{m}$ spacing), using the Zeiss microscope; or (2) a higher resolution $9 \times 7$ array spanning $200 \times 160 \mu \mathrm{m}$ of the slice $(20 \mu \mathrm{m}$ spacing), using the Olympus microscope. Uncaging spots $40 \mu \mathrm{m}$ in diameter were randomly targeted to each site at $5 \mathrm{~s}$ intervals. Using this systematic mapping paradigm, each photolysis event excited the same number but different spatial subsets of granule cells (Walter et al., 2009).

To test the reproducibility of the recording conditions and maps, in a few experiments we generated maps in triplicate and did not observe any significant differences in the overall response patterns (data not shown), showing that single maps reliably represented the activation pattern of a given Purkinje cell.

Whole-cell recording and electrical stimulation. Patch electrodes were pulled from borosilicate glass with a resistance of 3-5 M $\Omega$ when filled with intracellular solution. Recordings were made at $35 \pm 1{ }^{\circ} \mathrm{C}$ using an Optopatch amplifier (Cairn), with pipettes positioned on the Purkinje cell soma. Purkinje cell IPSCs were recorded under whole-cell voltage clamp, with internal solution containing the following (in $\mathrm{mm}$ ): 138 $\mathrm{CsCl}, 10 \mathrm{CsF}, 10$ HEPES, 3 MgATP, 2 QX-314, pH 7.2 with CsOH. The use of cesium allowed for a better space clamp and more accurate recording of IPSCs. With this high-chloride solution effecting symmetric external and internal chloride concentrations, GABAergic currents were inward when the cell was held at $-60 \mathrm{mV}$.

Purkinje cells were whole-cell voltage clamped at $-60 \mathrm{mV}$ and IPSCs were recorded in response to electrical stimulation in the molecular layer. For these experiments, $10 \mu \mathrm{M}$ 6-cyano-7-nitroquinoxaline-2, 3-dione (CNQX) (Tocris) was included in the bath to block excitatory transmission. Current pulses were delivered through glass electrodes (tip width same as patch pipettes) and targeted at the molecular layer interneurons around the Purkinje cell under study. The duration was set to $150 \mu$ s and the intensity was adjusted between 10 and $20 \mu$ A to elicit a clear response. The protocol was repeated to achieve 60-90 trials per cell. Cells were included in the analysis only if the series resistance was $<12 \mathrm{M} \Omega$ and remained stable (within 20\% change) throughout the recording.

Pharmacology. When noted, specific blockers of inhibitory synaptic transmission were bath-applied to the following final concentrations: $20-100 \mu \mathrm{M}$ picrotoxin (Sigma-Aldrich); $1 \mu \mathrm{M}$ (2S)-3-(1S)-1-(3,4-dichlorophenyl)ethyl amino-2-hydroxypropyl)(phenylmethyl)phosphinic acid hydrochloride (CGP 55845) (Tocris); $10 \mu \mathrm{M}$ 6-imino-3-(4-methoxyphenyl)1(6H)pyridazin butanoic acid hydrobromide (SR 95531) (Tocris). Ten micromolar CNQX (Tocris) was applied during whole-cell recording of Purkinje cell IPSCs to block excitatory synaptic transmission. Based on the average of all recordings made in the course of the study, there was no significant difference between the predominant baseline spontaneous firing rates of Purkinje cells before and after application of picrotoxin (control, $n=48: 41.4 \pm 1.3$ spikes/s; picrotoxin, $n=25: 40.4 \pm 2.4$ spikes/s; $p=0.55$, Student's $t$ test). However, the coefficient of variation of baseline interspike intervals, which is a measure of the regularity of Purkinje cell firing, significantly decreased (control, $0.12 \pm 0.006$; picrotoxin, $0.09 \pm 0.006 ; p=0.0002$, Student's $t$ test), showing that inhibition was relatively intact in the control condition, and effectively blocked after picrotoxin treatment (Häusser and Clark, 1997). Compiled data are reported as means \pm SEM. In two experiments, we substituted picrotoxin with SR 95531 and obtained comparable maps to those using picrotoxin (data not shown). These data were thus pooled in the analysis.

Analysis. Data were sampled at $10 \mathrm{kHz}$ using a National Instruments analog-to-digital-digital-to-analog card (PCI-MIO-16XE) and a Dell computer. Data acquisition and analysis were performed using LabView software written in-house. The predominant (mode) instantaneous baseline firing rate (FR) was determined by calculating the reciprocal of the predominant interspike interval (ISI) of the recording. Maximum and minimum post-photolysis instantaneous FRs were calculated as the reciprocal of the shortest ISI in the response $\left(\mathrm{FR}_{\max }\right.$, in the case of firing rate increases) or the reciprocal of the pause duration $\left(\mathrm{FR}_{\mathrm{min}}\right.$, in the case of pauses in firing, to denote firing rate decreases). The data were primarily illustrated in pseudocolor maps of post-photolysis change in firing rate $(\Delta \mathrm{FR})$, obtained by subtracting the predominant baseline firing rate from $\mathrm{FR}_{\max }$ and $\mathrm{FR}_{\min }$ (depending on the classification of the response) elicited at each photolysis target. In the pseudocolor maps, gray areas represent sites where glutamate photolysis directly activated the dendrites of the recorded Purkinje cell. The white pixels represent sites in which no data were obtained due to occasional stimulation failures or noise. IPLab or Origin was used to align pseudocolor maps along a coordinate grid, with the recorded Purkinje cell soma centered at the origin, and the Purkinje cell layer as the horizontal axis. IPLab or Origin was also used to generate the collapsed response profiles; regions of interest were collapsed along the vertical axis and pixel intensity was averaged across cells. In some instances, these response profiles were also folded horizontally along the axis of the Purkinje cell soma.

In a set of experiments, response maps before and after blocking inhibition were obtained from five adult cerebellar slices. The response profiles and the effects of blocking inhibition in the adults were qualitatively comparable with those seen in the juvenile animals, and thus these data are not shown.

Identification of response types. Individual granule cell patches were assigned to one of five different response categories: purely inhibitory, net inhibitory, net excitatory, purely excitatory, or not connected. A 
A
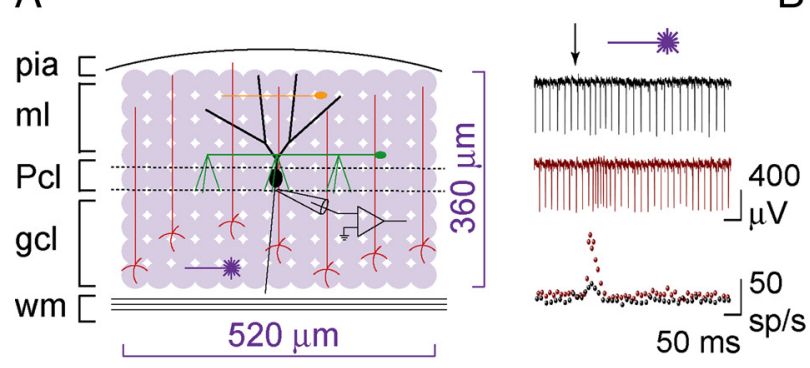

B

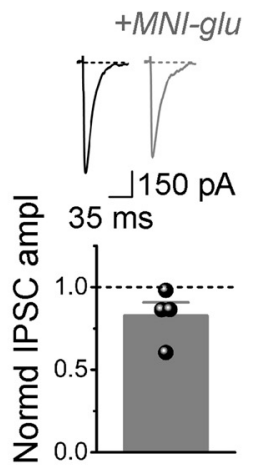

C

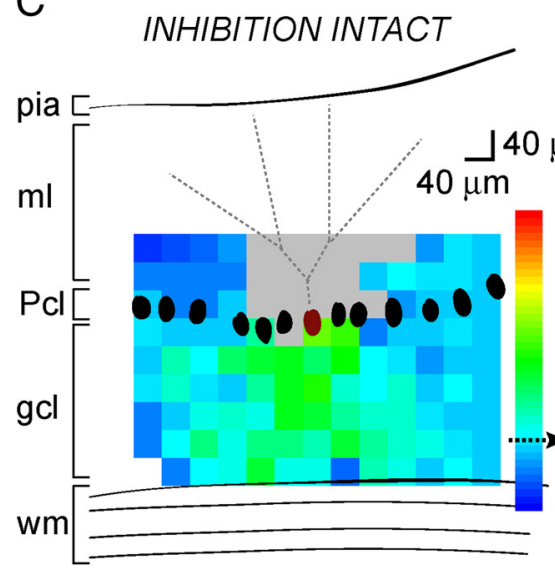

D

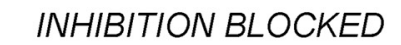

E

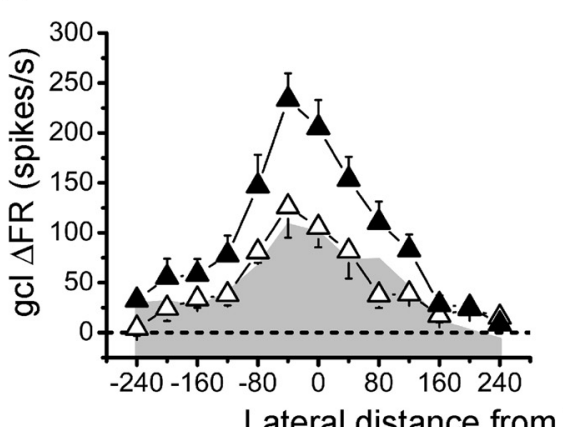

Lateral distance from
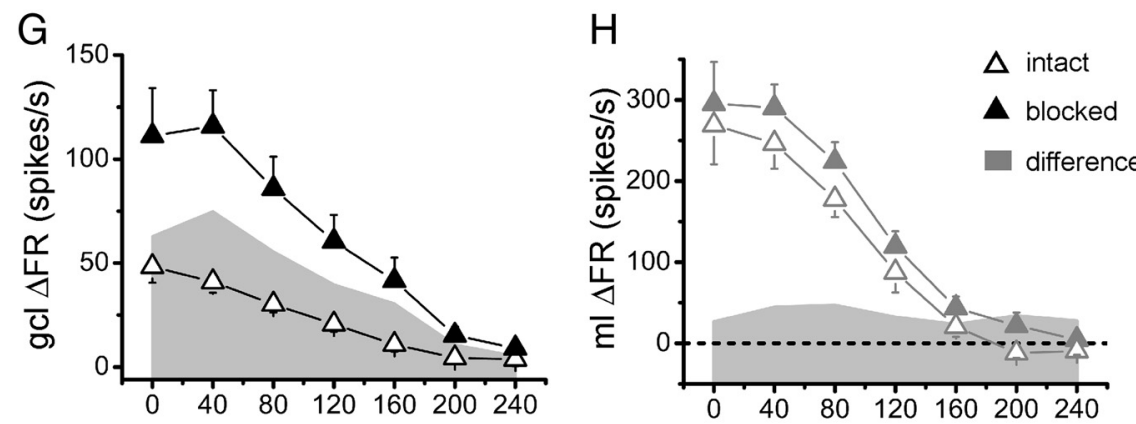

Lateral distance from Purkinje cell soma $(\mu \mathrm{m})$

Figure 1. In the sagittal orientation, increases in Purkinje cell output are evoked by granule cells underlying the Purkinje cell. $\boldsymbol{A}$, Left, Schematic of cerebellar cortex and sagittal photostimulation mapping paradigm. Extracellular recordings were made from an individual Purkinje cell as glutamate was systematically photoreleased with $40 \mu \mathrm{m}$ spacing over a $520 \times 360 \mu \mathrm{m}$ region of the cerebellar slice. ml, Molecular layer; Pcl, Purkinje cell layer; gcl, granule cell layer; wm, white matter; black, Purkinje cell; red, granule cell; green, basket cell; orange, stellate cell. Right, Top, Sample extracellular recordings from a Purkinje cell with inhibition intact (black) and blocked (burgundy). Glutamate was photoreleased at the time indicated by the arrow. Bottom, Corresponding plots of instantaneous firing rate versus time. $\boldsymbol{B}$, Purkinje cells were whole-cell voltage clamped at $-60 \mathrm{mV}$, and IPSCs were recorded in response to electrical stimulation of molecular layer interneurons, in the absence and presence of $250 \mu \mathrm{M} \mathrm{MNI-caged-}$ L-glutamate. CNQX was present throughout the experiment to block excitatory transmission. Top, Sample recordings. Bottom, The response was designated either as purely or net inhibitory (i.e., a "pause") or as purely or net excitatory if an ISI within $100 \mathrm{~ms}$ postphotolysis was different from the baseline predominant ISI by $>2$ SDs. If an inhibitory response with inhibition intact was converted to no response when inhibition was blocked (i.e., $\Delta \mathrm{FR}_{\text {intact }}<0$ and $\Delta \mathrm{FR}_{\text {blocked }}=0$ ), then the patch was assigned as purely inhibitory. If an inhibitory response with inhibition intact converted to an excitatory one (i.e., $\Delta \mathrm{FR}_{\text {intact }}<$ 0 and $\Delta \mathrm{FR}_{\text {blocked }}>0$ ), then the patch was assigned as being net inhibitory. If blocking inhibition either increased the amplitude of an excitatory response, or converted a patch that did not elicit a response when inhibition was intact to one that was excitatory with inhibition blocked (i.e., $\Delta \mathrm{FR}_{\text {intact }} \geq 0$ and $\left.\Delta \mathrm{FR}_{\text {blocked }}>0, \Delta \mathrm{FR}_{\text {diff }}>0\right)$, then the patch was assigned as net excitatory. If blocking inhibition did not increase the amplitude of an excitatory response $\left(\Delta \mathrm{FR}_{\text {intact }}>0\right.$, $\left.\Delta \mathrm{FR}_{\text {blocked }}>0, \Delta \mathrm{FR}_{\text {diff }}=0\right)$, then the patch was assigned as purely excitatory.

\section{Results}

In the sagittal orientation, increases in Purkinje cell output are evoked by granule cells underlying the Purkinje cell

We systematically photoreleased glutamate over 40 - $\mu \mathrm{m}$-diameter patches of

$\leftarrow$

average amplitude of evoked IPSCs in the presence of caged glutamate normalized to the average amplitude in the control condition. C, D, Maximum and minimum instantaneous postphotolysis firing rate responses to glutamate photorelease of a single Purkinje cell (burgundy) were converted to postphotolysis change in firing rate relative to baseline $(\Delta F R)$, pseudocolored, and plotted at the corresponding photolysis sites to generate Purkinje cell response maps. The baseline firing rate of the example cell shown was 48 spikes $/ \mathrm{s}$ with inhibition intact (C), and 52 spikes/s with inhibition blocked (D). The gray areas represent dendritic sites where glutamate photolysis directly targeted the recorded Purkinje cell. The white pixels represent sites in which no data were obtained due to stimulation failures or noise. $\boldsymbol{E}, \boldsymbol{F}$, Lateral profiles of the responses of a single Purkinje cell to glutamate photorelease in the sagittal orientation in the granule cell layer $(\boldsymbol{E})$ or the molecular layer $(\boldsymbol{F})$ were generated by averaging the responses along each $40-\mu \mathrm{m}$-wide column and plotting the results as a function of lateral distance from the soma of the recorded Purkinje cell. Data are from the Purkinje cell shown in $\boldsymbol{C}$ and $\boldsymbol{D}$. The open and closed triangles denote responses with inhibition intact and blocked, respectively. The shaded gray area plots show the difference in change in firing rate between the two conditions. $\mathbf{G}, \boldsymbol{H}$, Compiled vertically collapsed average profiles of Purkinje cell responses to glutamate photorelease in the sagittal orientation in the granule cell layer ( $G$; control, $n=27$; picrotoxin, $n=9)$ or the molecular layer $(\boldsymbol{H}$; control, $n=8$; picrotoxin $n=8$ ). The data are folded along the vertical axes of the Purkinje cells. The average change in firing rate from baseline is plotted as a function of lateral distance from the soma of the recorded Purkinje cell. The open and closed triangles denote responses with inhibition intact and blocked, respectively. The gray area plots show the difference in change in firing rate between the two conditions. 
A

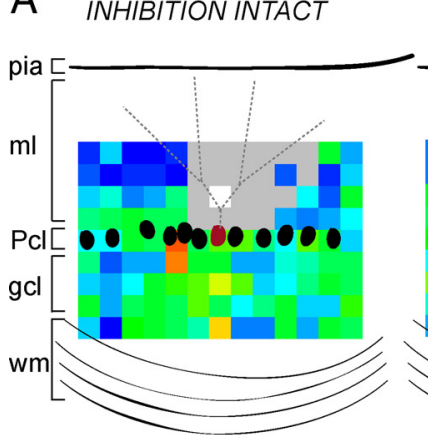

CGP 55845 ONLY

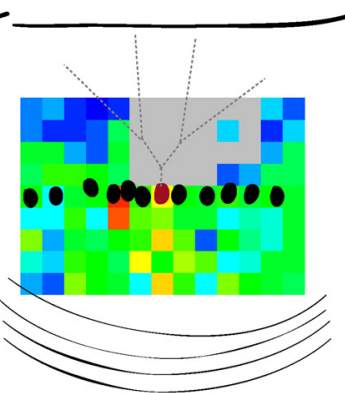

CGP $55845+$ PICROTOXIN

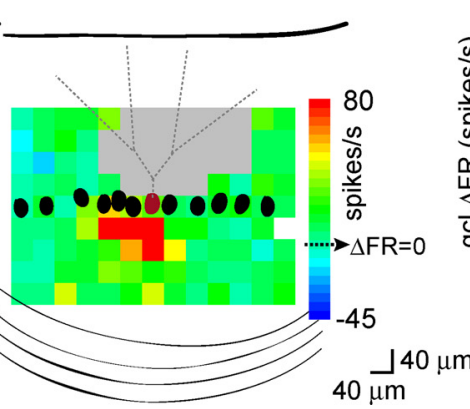

B

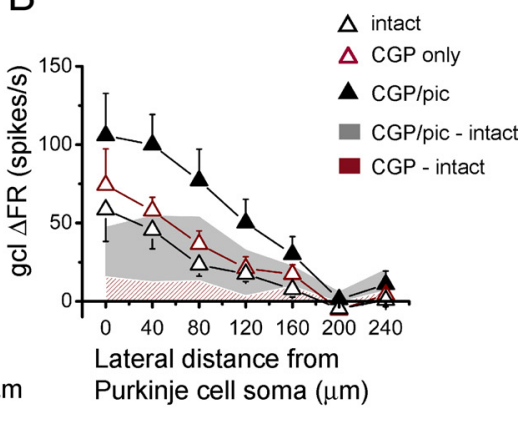

Figure 2. Inhibition mediated by $G A B A_{B}$ receptors does not significantly shape Purkinje cell response patterns. $A$, Sample pseudocolor sagittal $\triangle F R$ maps of the same Purkinje cell with inhibition intact (left), with only $G_{A B A_{B}}$ receptors blocked (middle), and with both $G_{A B A_{B}}$ and $G_{A B A_{A}}$ receptors blocked (right). The baseline firing rates of this cell in the three conditions were 48 , 48 , and 53 spikes/s, respectively. The gray areas represent dendritic sites where glutamate photolysis directly targeted the recorded Purkinje cell. The white pixels represent sites in which no data was obtained due to stimulation failures or noise. $B$, Average vertically collapsed profiles of Purkinje cell responses to glutamate photorelease in the granule cell layer with inhibition intact (open black triangles), with only $G A B A_{B}$ receptors blocked (open burgundy triangles), and with both $G A B A_{B}$ and $G A B A_{A}$ receptors blocked (closed black triangles). The average change in firing rate from baseline from five cells is plotted as a function of lateral distance from the soma of the recorded Purkinje cell. Area plots showing the differences in change in firing rate between conditions are superimposed.

\section{A INHIBITION INTACT}

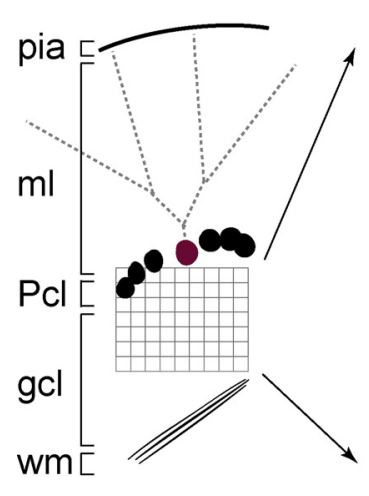

\section{B}
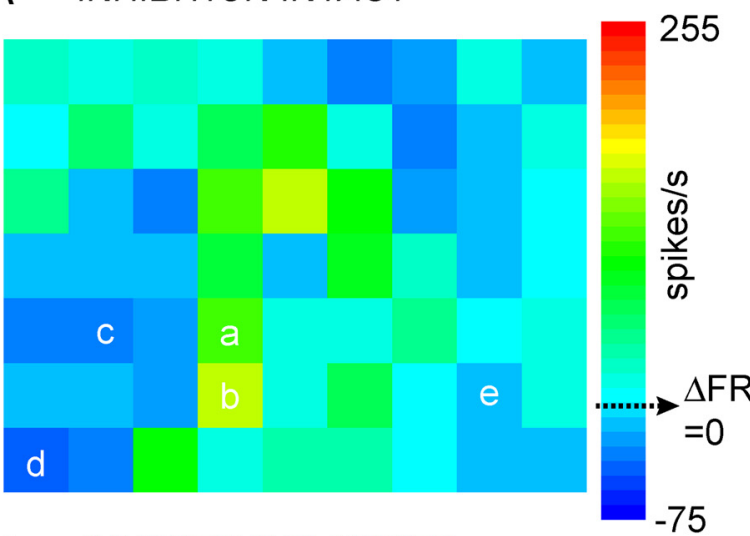

B INHIBITION BLOCKED
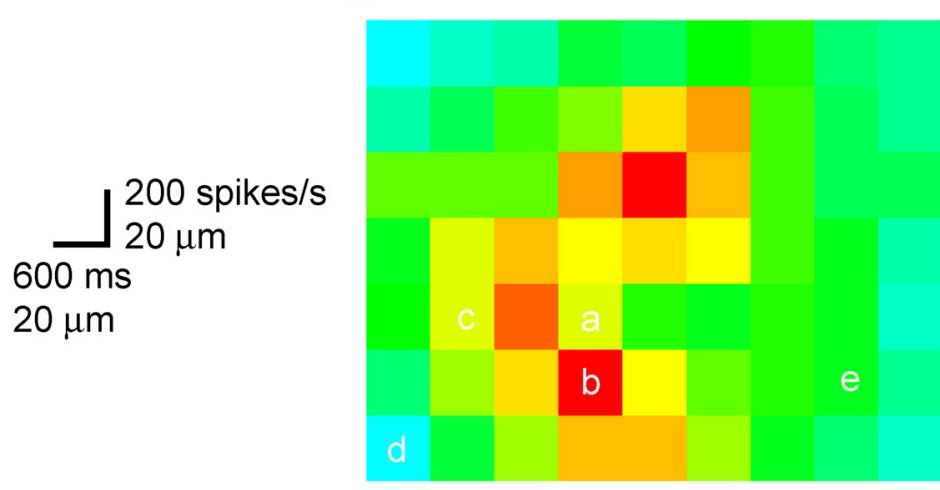
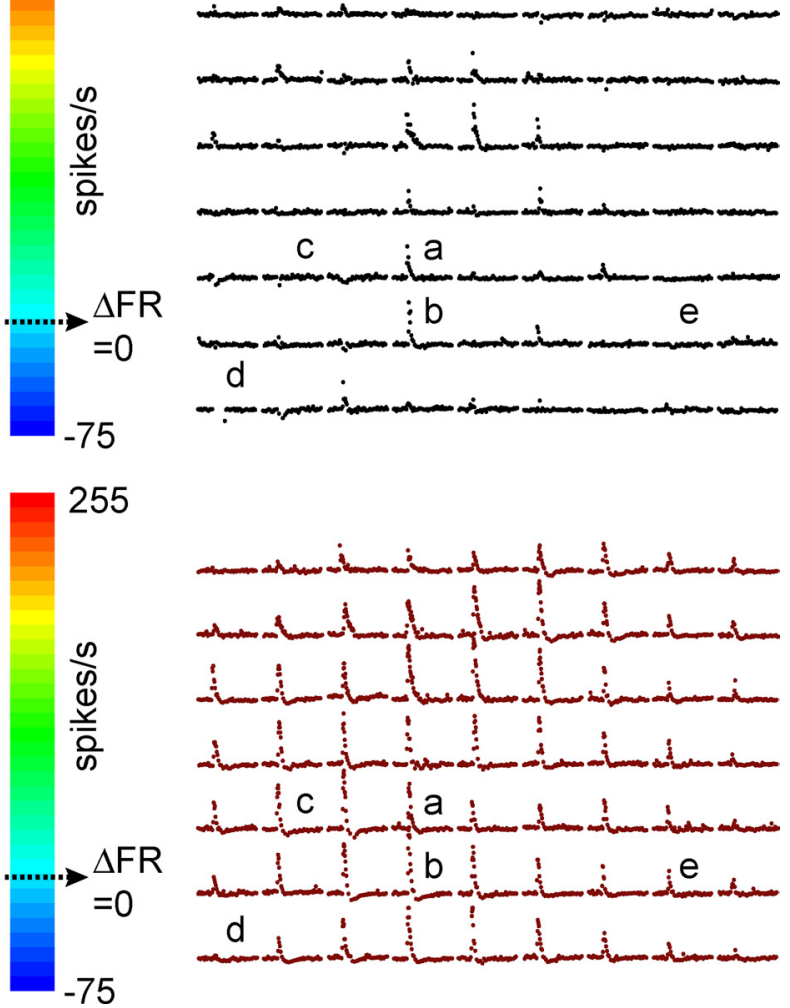

Figure 3. Photostimulation of discrete granule cell patches elicits a variety of Purkinje cell responses. $A$, Pseudocolor $\Delta F R$ map of the change in post-photolysis instantaneous firing rate ( $\Delta F R$ ) of the recorded Purkinje cell (burgundy) schematized on the left, with inhibition intact. Different response types are labeled $a-e$ and described in Results. The corresponding map of instantaneous firing rate versus time responses of the same Purkinje cell is shown on the right. $B$, Same cell as in $A$, but with inhibition blocked. The baseline firing rate of this cell was 48 spikes/s with both inhibition intact and blocked.

granule cells in juvenile rat cerebellar slices while recording the activity of a single overlying Purkinje cell. Figure $1 A$ shows a schematic of the pattern of photolytic stimulation across a $520 \times 360$ region of the slice in the sagittal orientation. Individual responses were monitored using extracellular recording. The post-photolysis instantaneous firing rates before and after blocking inhibition (Fig. $1 \mathrm{~A}$, right) were first converted to changes in instantaneous firing rate relative to the baseline firing rate of the cell $(\Delta \mathrm{FR})$. These values were then pseudocolored and superimposed on scaled schematics of the recorded Purkinje cell to create Purkinje cell response maps (Fig. 1C,D).

MNI-caged-L-glutamate has been reported to block $\mathrm{GABA}_{\mathrm{A}}$ receptors (Fino et al., 2009). Because for our experiments it is important to minimally affect GABAergic transmission, we explored the extent of this blockade. As shown in Figure $1 B$, 


\section{A \\ INHIBITION INTACT \\ B INHIBITION BLOCKED \\ C DIFFERENCE}

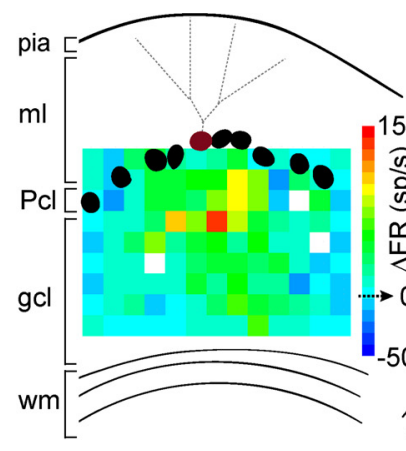

$\mathrm{D}$
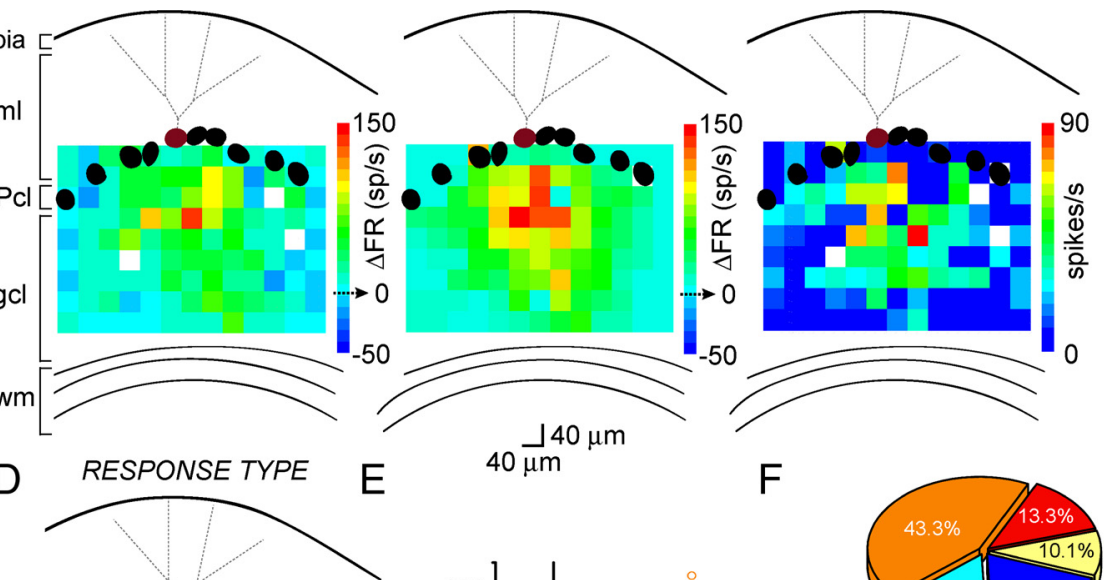

$40 \stackrel{\lrcorner}{\mu \mathrm{m}}$

E
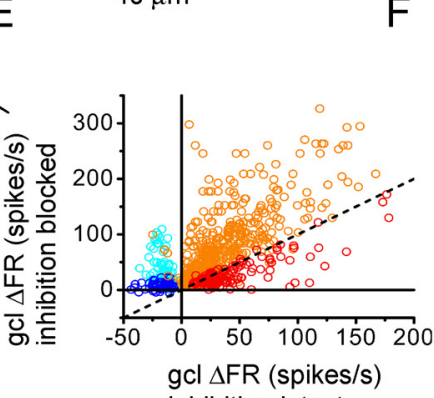
inhibition intact

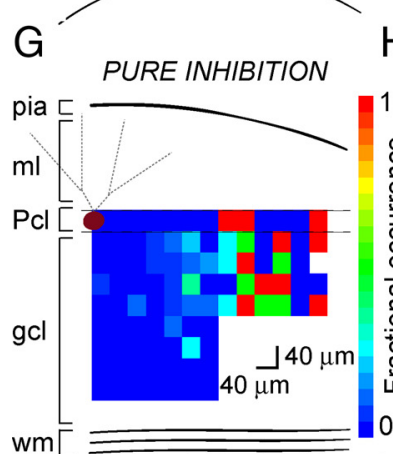

$\mathrm{H}$
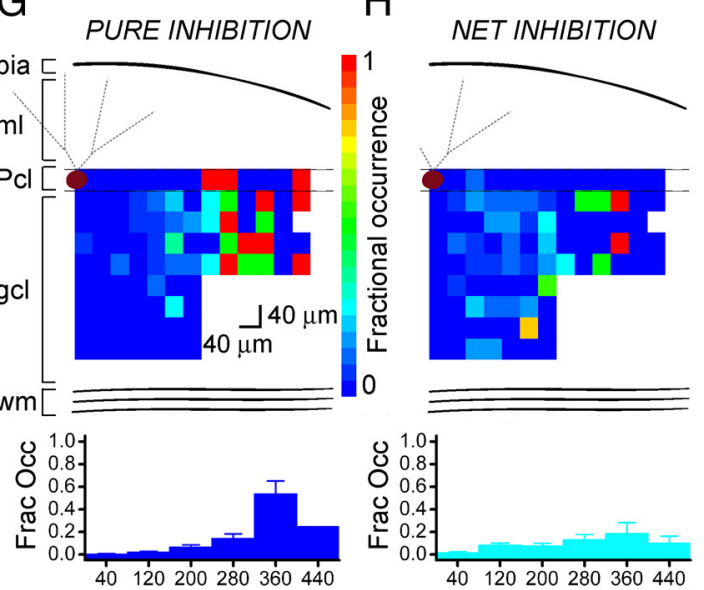

Lateral distance from Purkinje cell soma $(\mu \mathrm{m})$

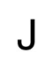

PURE EXCITATION K

NOT CONNECTED

EXTENT OF MODULATION
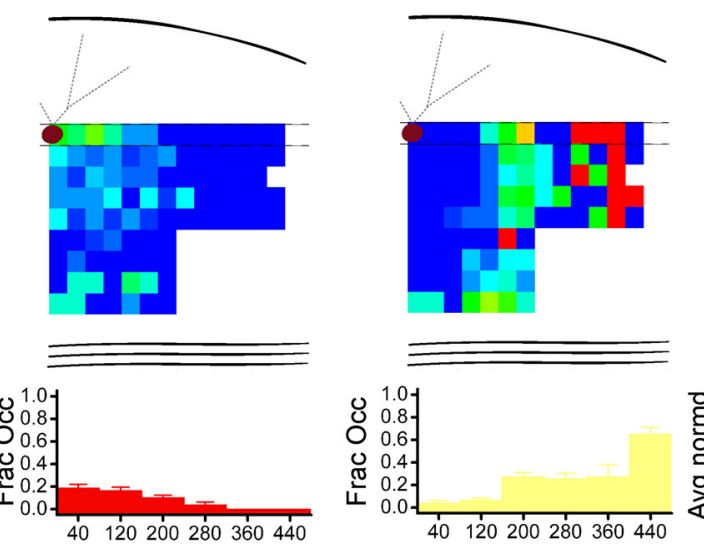

Lateral distance from Purkinje cell soma $(\mu \mathrm{m})$

Figure 4. The different response types are stereotypically organized. $A, B$, Pseudocolor response maps of a single Purkinje cell in terms of change in firing rate with respect to baseline $(\Delta F R)$, with inhibition intact $(\boldsymbol{A})$ or blocked $(\boldsymbol{B})$. The baseline firing rates voltage-clamp recordings from Purkinje cells showed a relatively weak (17\%) reduction in the amplitude of evoked IPSCs by the caged glutamate added to the slice under our experimental conditions (control, $599 \pm 57 \mathrm{pA}$; caged glutamate, $504 \pm$ $76 \mathrm{pA} ; p=0.36 ; n=4)$.

The mapping experiments showed that under control conditions with inhibition intact, increases in firing rate were elicited by granule cell patches located medially relative to the recorded Purkinje cells. Decreases in firing rates, or pauses, were elicited by granule cell patches located laterally. This response pattern is illustrated by the map shown in Figure $1 C$. Blocking inhibition in the same cell by adding picrotoxin to the recording bath (Fig. $1 D$ ) altered this pattern. Pauses were no longer elicited laterally and a wider region of granule cells now excited the Purkinje cell.

To quantify and compare the shape of these response patterns, we generated lateral response profiles. The $\Delta \mathrm{FR}$ values were averaged along each $40-\mu \mathrm{m}$-wide column and plotted relative to the lateral position of the recorded Purkinje cell (Fig. $1 E)$. Figure $1 G$ shows that this pattern was consistent across different cells, as seen in the average response profiles of 27 cells with inhibition intact and 9 cells with inhibition blocked.

To rule out the possibility that the altered map patterns were either due to a change in input resistance or a narrow dendritic spread of juvenile Purkinje cells, we systematically photoreleased glutamate at the molecular layer to directly stimulate Purkinje cell dendrites (Fig.

\section{$\leftarrow$}

of the cell were 36 and 41 spikes/s, respectively. C, From the same cell as in $\boldsymbol{A}$ and $\boldsymbol{B}$, the difference map generated by subtracting the values in $\boldsymbol{A}$ from those in $\boldsymbol{B}$. $\boldsymbol{D}$, The responses of the same Purkinje cell as in $\boldsymbol{A}-\boldsymbol{C}$ were color-coded according to response type (see $\boldsymbol{F}$ for legend). $\boldsymbol{E}$, The responses evoked from granule cell photostimulation in 12 cells are plotted in terms of change in firing rate with inhibition blocked, as a function of change in firing rate with inhibition intact, and colored according to their response type (see $\boldsymbol{F}$ for legend), assigned as described in Materials and Methods. The plot shows a wide range in which inhibition can modulate Purkinje cell output. $\boldsymbol{F}$, The distribution of response types obtained from two cells in which the recorded Purkinje cell was placed at the edge of the photolysis grid. $\mathbf{G}-\boldsymbol{K}$, Top, The average probability of obtaining one of the five response types at each map coordinate, calculated from 12 cells. The number of a given response type at each map coordinate was divided by the total number of cells sampled at that coordinate, to yield the fractional occurrence of each response. Bottom, Vertically collapsed averages from the overlying maps, binned at $80 \mu \mathrm{m}$. $\boldsymbol{L}$, An average $\Delta \mathrm{FR}$ difference map as in C was generated from 12 individual maps. The data were normalized to the maximum difference. 
$1 F, H)$. This allowed us to map the extent of the dendritic tree, as well as to check whether there were any alterations in the shape of the response profile after blocking inhibition. Figure $1 \mathrm{~F}$ shows the molecular layer response profile of the same cell as in Figure $1 C-E$. In contrast to the non-uniform changes seen when photolysis was directed at the granule cell layer, photolysis at the dendrites revealed a constant change in firing rate after blocking inhibition. This was consistent across eight cells, as shown in the average molecular layer response profile in Figure $1 \mathrm{H}$. This profile also reflects the average spread and orientation of dendritic trees of the sampled Purkinje cells. The dendrites extended a total of $\approx 320 \mu \mathrm{m}$, with a half-width of $\approx 230 \mu \mathrm{m}$ (Fig. $1 \mathrm{H}$ ), comparable with the half-width of the granule cell layer response profile after blocking inhibition $(\approx 240 \mu \mathrm{m})$.

\section{Inhibition mediated by $\mathrm{GABA}_{\mathrm{B}}$ receptors does not significantly shape Purkinje cell response patterns} The experiments above using picrotoxin only blocked inhibition mediated by $\mathrm{GABA}_{\mathrm{A}}$ receptors. However, GABA released by basket and stellate cells also activates metabotropic $\mathrm{GABA}_{\mathrm{B}}$ receptors on Purkinje cells. We next tested whether $\mathrm{GABA}_{\mathrm{B}}$ receptor-mediated inhibition contributes to the alteration in Purkinje cell response patterns.

The Purkinje cell response maps shown in Figure $2 A$ and the compiled average response profiles of five experiments (Fig. $2 B$ ) show that blocking $\mathrm{GABA}_{\mathrm{B}}$ receptors alone using CGP $55845 \mathrm{did}$ not alter the response pattern. Instead, it only increased the postphotolysis firing rate throughout. The majority of laterally elicited pauses present in the intact condition persisted when CGP 55845 was applied. These were only eliminated upon subsequent application of picrotoxin. The data suggest that $\mathrm{GABA}_{\mathrm{B}}$ receptormediated inhibition contributes little to the pattern of Purkinje cell activation.

\section{Photostimulation of different granule cell patches elicits a variety of Purkinje cell responses}

In one set of experiments, we adjusted our photolysis paradigm to achieve higher resolution, such that uncaging sites were spaced at $20 \mu \mathrm{m}$ (Fig. 3). For each stimulation site, we plotted the instantaneous firing rates of the recorded Purkinje cell (reciprocal of interspike interval) flanking photolysis onset to illustrate the type and kinetics of each response.

With inhibition intact, photoreleasing glutamate over the different patches of granule cells drove a variety of responses in the recorded Purkinje cell. For example, in Figure $3 A$, photostimulation of granule cells at site $a$ drove a moderate increase in the firing rate of the Purkinje cell from baseline; at site $b$, the cell was driven to an even higher maximum firing rate; at sites $c$ and $d$, the firing rate decreased from baseline; and at site $e$, the firing rate remained unchanged. Figure $3 B$ illustrates the activation pattern of the same Purkinje cell as in Figure $3 A$, but with inhibition blocked. The map clearly shows a different set of responses compared with when inhibition was intact. Stimulating sites $a$ and $b$ now drove the cell to fire at higher rates; the firing rate decrease at site $c$ was converted to a firing rate increase; site $d$ elicited no change in firing rate from baseline instead of a pause; and site $e$ now drove a firing rate increase. Therefore blocking inhibition either (1) drove the cell to fire at a higher frequency $(a, b) ;(2)$ eliminated any post-photolysis decrease, or pause, in firing rate $(c-e)$; or (3) had no effect.

The relative contributions of excitation and inhibition to the response of the Purkinje cell were determined by comparing the difference in $\Delta$ FR between before and after blocking inhibition as shown in the pseudocolor maps. Interestingly, granule cell patches that were directly adjacent were capable of eliciting very distinct responses.

\section{The different response types are stereotypically organized}

We next determined the relative spatial distribution of different response types within the regions sampled. Figure $4, A$ and $B$, shows $\Delta$ FR activation maps of the same Purkinje cell with inhibition intact or blocked, respectively. Figure $4 C$ shows the map of their difference-the $\Delta$ FR values with inhibition intact were subtracted from the $\Delta \mathrm{FR}$ values with inhibition blocked. Differences were used to assign granule cell patches as either purely inhibitory, net inhibitory, net excitatory, purely excitatory, or not connected (for details, see Materials and Methods), and maps of response type were created (Fig. $4 D$ ).

We analyzed 12 cells in which sagittal maps with comparable contours and flat Purkinje cell layers were obtained with both inhibition intact and blocked. Figure $4 E$ plots all of the responses analyzed in these cells. The plot shows that there was a wide range in the differences in firing rate between before and after blocking inhibition, suggesting a wide range in which inhibition can modulate the firing rate of Purkinje cells. The majority of responses had a larger response after blocking inhibition compared with when inhibition was intact and were thus net excitatory (orange). 
A

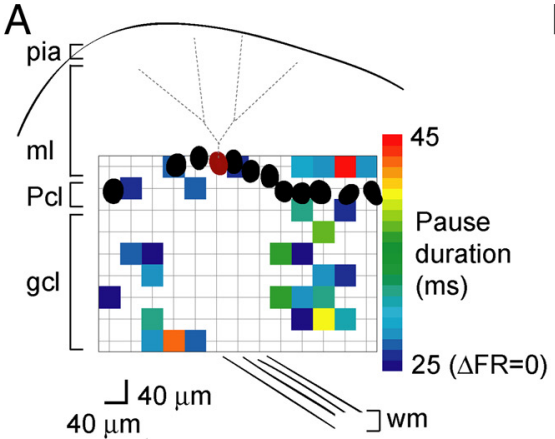

C

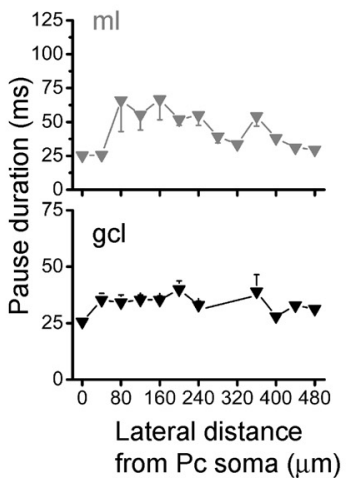

$\mathrm{B}$

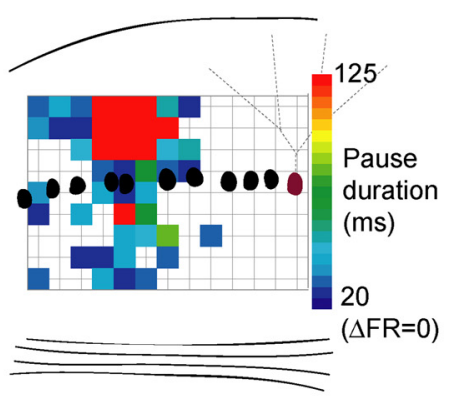

$\mathrm{E}$

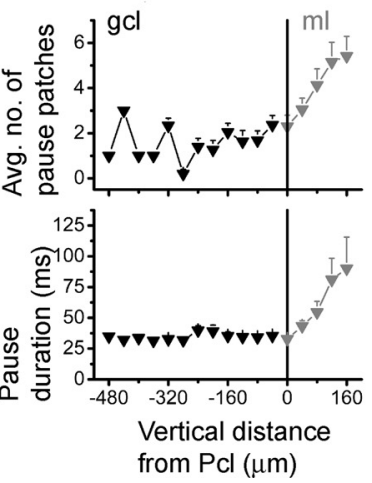

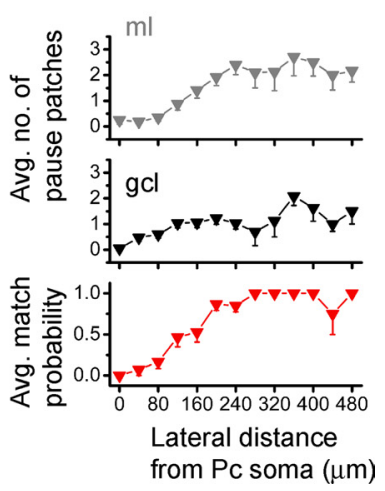

Figure 6. In the sagittal orientation, decreases in Purkinjecell firing are mainly elicited by laterally positioned granule cells. $A, B$, Sample pseudocolor sagittal Purkinje cell maps of post-photolysis pause duration for two different Purkinje cells (burgundy) with one centered $(\boldsymbol{A})$ and the second positioned at the edge $(\boldsymbol{B})$ of the photolysis grid. The lower limits on the color scales indicate the interspike interval corresponding to the spontaneous firing rates of the cells. $\boldsymbol{C}$, The average duration of pauses elicited in the recorded Purkinje cell by glutamate photolysis over the granule cell layer (black) and molecular layer (gray), plotted as a function of lateral position relative to the soma of the recorded Purkinje cell. Data were averaged from 20 cells. D, Same as $C$, but plotting the number of sites from the same 20 cells that elicited pauses as a function of vertical position relative to the Purkinje cell layer. $\boldsymbol{E}$, Top and Middle, The average number of postphotolysis pauses as a function of lateral distance from the recorded Purkinje cell, from the same 20 cells. Bottom, For every pause elicited in the granule cell layer, the probability of eliciting a pause from the molecular layer at the same lateral distance from the recorded Purkinje cell was plotted.

To obtain a more accurate picture of the proportion of response types, we sampled a wider lateral range of granule cells by positioning the Purkinje cell at the lateral edge of the field of view rather than at its center. Figure $4 F$ shows the distribution of response types obtained from two cells that were positioned at the edge of the photolysis grid. With this modification, granule cells as far lateral as $480 \mu \mathrm{m}$ from the recorded Purkinje cell were activated by photostimulation. In these cells, most $(\approx 43 \%)$ responses exhibited mixed excitation (orange); purely excitatory responses made up $\approx 13 \%$ of the maps (red); and patches that mediated inhibition (blue and cyan) comprised $\approx 34 \%$ of responses ( $\approx 19 \%$ pure inhibition; $\approx 15 \%$ net inhibition). Approximately $10 \%$ of patches were seemingly not connected to the recorded Purkinje cell.

In 12 cells, to quantify the average occurrence of each response type, we counted the number of a given response type at each map coordinate, and divided that value by the total number of cells sampled at that coordinate. This yielded maps of the probability of eliciting a specific type of response, shown in Figure $4 G-K$. The probability that pure and net inhibitory responses were elicited by granule cells increased as a function of lateral distance from the Purkinje cell. Conversely, the probability that pure and net excitatory responses were elicited by granule cells decreased as a function of lateral distance from the Purkinje cell. Interestingly, within the distance examined, the probability that granule cells provided net inhibition to Purkinje cells had a clear peak at

patches positioned $340-400 \mu \mathrm{m}$-in the graph, represented by the bar centered about $360 \mu \mathrm{m}$.

To further test whether there was a pattern to the extent of modulation of excitation by inhibition, we created individual $\Delta$ FR difference maps for these 12 cells as in Figure $4 C$, but only for mixed (net excitation) patches, to generate the average map shown in Figure $4 L$. The values were normalized to the highest difference in $\Delta \mathrm{FR}$. The compilation shows that the strongest differences were mediated by the region directly underlying and medial to the recorded Purkinje cell.

We next took advantage of these extended maps to quantify the extent to which inhibition modulated the firing rate of Purkinje cells. Figure $5 A$ shows the average $\Delta$ FR maps of these cells before and after blocking inhibition. The average differences between these values for granule cell patches that mediated inhibition (whether net excitatory or inhibitory, or purely inhibitory) are shown in Figure $5 B$. The vertically collapsed average response profiles generated from these maps are shown in Figure 5, $C$ and $D$. The impact of laterally positioned granule cells in reducing the firing rate of Purkinje cells is easily discernible in these maps.

\section{In the sagittal orientation, decreases in} Purkinje cell firing are mainly elicited by laterally positioned granule cells

We quantified the extent of pure inhibition in the sagittal orientation by generating maps of pauses and pseudocolored these maps according to the duration of the pause in the Purkinje cell (Fig. $6 A, B$ ). In agreement with the average data shown in Figure 4, $G$ and $H$, pauses occurred lateral to the Purkinje cell, increasing in frequency from a distance of $\sim 100 \mu \mathrm{m}$ from the Purkinje cell, extending to the edges of the maps, both laterally and vertically. Despite the increase in the frequency in the patches that produced pauses as a function of lateral distance, there was no correlation between the duration of the pauses and lateral distance (Fig. 6C). To determine whether pauses occurred with any specific pattern in the vertical orientation (Zhang and Linden, 2010), we also analyzed the average number of sites that elicited pauses as well as the average duration of the pauses, as a function of vertical distance from the Purkinje cell layer. In the granule cell layer, there was no correlation between the average pause duration or the number of granule cell patches that elicited a pause as a function of vertical distance (Fig. 6D). However, when interneurons were directly activated by photorelease of glutamate in the molecular layer, both the pause duration and the number of sites that elicited a pause increased monotonically up to $160 \mu \mathrm{m}$ (the furthest vertical distance examined) (Fig. $6 \mathrm{D}$ ). These latter data more likely represent the extent of the dendritic tree of interneurons sampled in the molecular layer.

We took advantage of the ability to directly activate interneurons in the molecular layer to map their connectivity with the recorded Purkinje cell $(n=7)$. This information was then used to 
correlate the location of interneurons in the molecular layer that inhibited Purkinje cells, with locations in the granule cell layer that elicited pauses in the same cells. The compilation of 20 maps shows that the average number of pause-eliciting patches relative to the Purkinje cell soma in both the granule cell and molecular layers increased with lateral distance from the recorded Purkinje cell (Fig. 6E, top and middle panels). A number of pauses were evoked from medial sites, as reflected in the averaged summary plots. However, these were far fewer compared with the number observed more laterally.

To examine whether a correlation existed between the locations of interneurons and granule cells that inhibited the cell, we calculated the probability of eliciting a pause from the molecular layer at the same lateral position in which a pause could be elicited from the granule cell layer. The analysis shows a strong correspondence between the lateral positions of pause-eliciting regions from the granule cell and molecular layers at lateral distances $>160 \mu \mathrm{m}$. This suggests that, consistent with the known anatomy, the axons of a patch of granule cells project straight up to the directly overlaying molecular layer, activating an interneuron or interneurons located at the same lateral distance from the given Purkinje cell, thus inhibiting that Purkinje cell. The lack of correspondence at distances $<160 \mu \mathrm{m}$ likely reflects a caveat of the experimental paradigm in which photorelease of glutamate in the molecular layer would not only activate the inhibitory interneurons but also directly excite the dendrites of Purkinje cells, which are likely to be most dense within this distance.

\section{In the coronal orientation, inhibition strongly, but uniformly, modulates excitation}

In the preceding sections, we found that patches of granule cells lateral to a Purkinje cell can synapse to molecular layer interneurons, which then inhibit that Purkinje cell. This lateral inhibition is consistent with the known cytoarchitecture of the cerebellar cortex in which axons of both basket and stellate cells course sagittally to connect to Purkinje cells. Given this anatomical organization of the axons of interneurons, one does not expect to see lateral inhibition in the coronal orientation. However, the possibility exists that granule cells that synapse onto Purkinje cells synapse with interneurons that also synapse with the same Purkinje cell, thus providing for feedforward inhibition. To test this hypothesis, we repeated the mapping experiments in coronal cerebellar slices (Fig. $7 A$ ). Figure $7 B$ shows $\Delta F R$ activation maps of the same coronally oriented Purkinje cell before and after blocking inhibition. While the excitatory receptive field was strengthened after blocking inhibition, in contrast to the sagittal orientation, the effect was uniform, with the general pattern unaltered. This was consistent across five maps, as shown in the compiled average of their collapsed response profiles (Fig. 7C). recorded Purkinje cell.
B
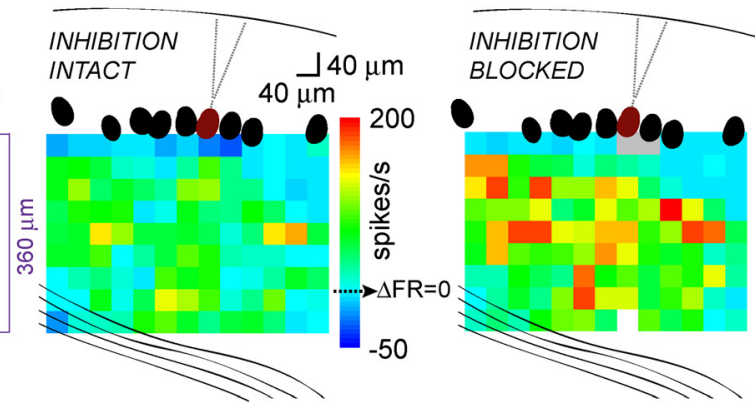

$\mathrm{D}$

$\mathrm{E}$

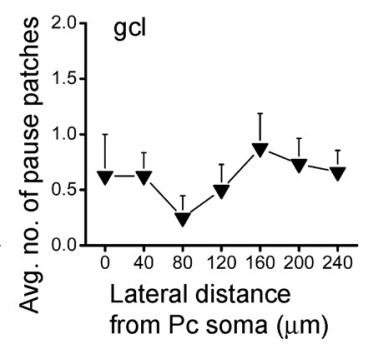

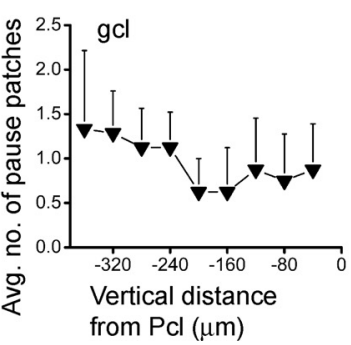

Figure 7. In the coronal orientation, inhibition strongly, but uniformly, modulates excitation. $A$, Schematic of photostimulation in figure $1 A$, but in the coronal orientation. $\boldsymbol{B}$, Sample pseudocolor coronal maps of change in postin e cell responses to glutamate photorelease in the granule cell layer. The average change in firing rate from baseline of five

Of the 13 Purkinje cells mapped in the coronal orientation with inhibition intact, 11 maps exhibited granule cell patches that decreased the firing rate of the Purkinje cell. These pause-eliciting granule cell patches were randomly distributed and not dominant laterally in coronal maps compared with the sagittal maps (Fig. $7 D, E$ ). Interestingly, however, the average post-photolysis change in firing rate after blocking inhibition was twice that when inhibition was left intact (Fig. 7C), a robust change that cannot be solely attributed to an increase in Purkinje cell input resistance. This twofold change is comparable with the highest changes elicited by the restricted medial region of granule cells in the sagittal orientation (Fig. 1E,G). The fact that granule cell patches eliciting pauses were randomly distributed in coronal maps (Fig. $7 D, E)$ is consistent with the idea that, within the range examined, interneurons mediate feedforward—and not lateral—inhibition.

\section{Discussion}

In this study, we sought to map the functional connectivity between granule cells, molecular layer interneurons, and Purkinje cells. To do so, we activated discrete patches of granule cells using glutamate photostimulation, which has been previously shown to activate these cells in a manner comparable with their activation in vivo with discrete sensory stimuli (Jaeger and Bower, 1994; Chadderton et al., 2004; Jörntell and Ekerot, 2006; Rancz et al., 2007; Walter and Khodakhah, 2009). We scanned the connectivity of a $360 \times 520 \mu \mathrm{m}$ region of granule cells with $40 \mu \mathrm{m}$ resolution. The latter corresponds to the spread of a mossy fiber branchlet in the coronal orientation (Sultan, 2001). 

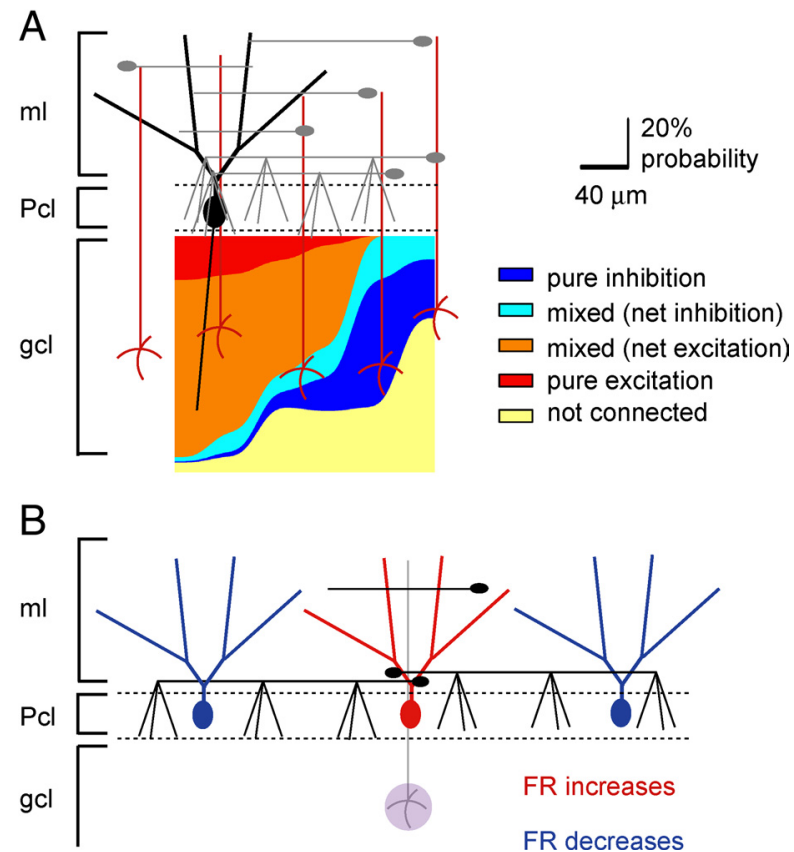

Figure 8. Summary schematics illustrating the functional organization of Purkinje cell responses. $A$, An idealized pseudocolor map of the activation pattern of an individual Purkinje cell was constructed based on the compiled probability data. The number of patches of a certain response type at a given lateral distance from the target Purkinje cells was divided by the total number of responses recorded at that distance. The data are plotted as stacked and smoothed area plots denoting the percentage probability of each of the five response types as a function of lateral position from the target Purkinje cell. $\boldsymbol{B}$, The data suggest that excitation of the same set of granule cells underlying a given Purkinje cell increases the firing rate of that Purkinje cell but decreases the firing rate of another Purkinje cell located along the same sagittal plane.

We found a remarkable stereotypic pattern of functional connectivity between granule cells and Purkinje cells. In the sagittal orientation, granule cells immediately medial to a given Purkinje cell elicited pure excitation, whereas granule cells located more laterally_as much as $480 \mu \mathrm{m}$ away-elicited pure inhibition (Fig. $8 A$ ). This is an example of classic lateral inhibition and agrees well with prior work suggesting its existence in the cerebellum (Andersen et al., 1964; Szentagothai, 1965; Eccles, 1973; Palay and Chan-Palay, 1974; Cohen and Yarom, 1998, 2000a,b; Gao et al., 2006). It is likely that patches of granule cells even more lateral than $480 \mu \mathrm{m}$ can inhibit Purkinje cells. This is because the length of interneuron axons range from 50 to $500 \mu \mathrm{m}$ in the sagittal orientation (Palay and Chan-Palay, 1974; Sultan and Bower, 1998). Our limited field of view prevented our scrutiny of inputs beyond $480 \mu \mathrm{m}$.

The lateral inhibition discussed, together with excitation of Purkinje cells immediately above a patch of granule cells, suggests the presence of an anatomical center-surround organization in the cerebellar cortex. Thus, activity of a mossy fiber excites the Purkinje cells positioned immediately above it and concurrently inhibits Purkinje cells on either side (Fig. $8 \mathrm{~B}$ ). Such a pattern of activation and lateral inhibition has been experimentally demonstrated by activating a beam of parallel fibers by electrical stimulation of the surface of the cerebellum (Cohen and Yarom, 1998, 2000a,b; Sullivan et al., 2005; Gao et al., 2006). However, although activation of a patch of granule cells by a mossy fiber will no doubt result in a center-surround pattern of activation at a single sagittal plane, it is less clear whether it will lead to activation of a beam of parallel fibers in vivo (Bower, 2010). Reassuringly, our findings are in agreement with recent in vivo imaging exper- iments that showed that peripheral stimulation activated a patch of Purkinje cells and concurrently inhibited flanking Purkinje cells in the sagittal orientation (Gao et al., 2006).

As stated, in the sagittal orientation granule cells underneath a Purkinje cell excited it and distant lateral granule cells mostly inhibited it. In the intermediate region that encompassed the width of the dendritic tree of the Purkinje cell, the impact of granule cells on the activity of that Purkinje cell was a systematic progression from net excitation to net inhibition. In this intermediate region, it is likely that some parallel fibers that directly excited a Purkinje cell also activated the interneurons that subsequently inhibited that Purkinje cell. These cases constitute feedforward inhibition that plays an important role in restricting the period during which a Purkinje cell is excited by synaptic input (Brunel et al., 2004; Mittmann et al., 2005).

A caveat of our experiments is that the results were obtained in acutely prepared cerebellar slices in which some of the connectivity would have been severed. However, the orientation and highly planar morphology of Purkinje cells and interneurons would reduce the impact of this slicing artifact on the data obtained. Nonetheless, while on the basis of the available in vivo data the pattern of excitation and its progression to inhibition likely remains under physiological conditions, the extent to which the profile changes as a function of lateral distance might be somewhat different in the intact cerebellum.

In contrast to that seen in the sagittal orientation, the role of interneurons in the coronal orientation was very different. In this orientation, inputs from all granule cells positioned throughout the $480 \mu \mathrm{m}$ range examined were comparably modified by inhibition. This was evident from the fact that the efficacy of granule cell patches increased uniformly when inhibition was blocked. The inhibition in the coronal orientation is most likely mediated by feedforward inhibition. The comparable efficacy of inhibition throughout the range examined in the coronal orientation is in agreement with the seemingly uniform effects of blocking inhibition in vivo when a beam of parallel fibers is excited (Gao et al., 2006; Santamaria et al., 2007). It is noteworthy that, while the experiments performed in the coronal orientation are also likely to suffer from the choice of slice as a preparation, in this orientation any impact of loss in the connectivity as a consequence of the slicing procedure is likely to have been uniform throughout.

In the cerebellar cortex, in addition to the inhibitory actions of molecular layer interneurons on Purkinje cells, Golgi cells inhibit granule cells. Since Golgi cells are spontaneously active and have been shown to remain so in slice (Dieudonne, 1998; Kanichay and Silver, 2008), it is perhaps plausible that some of the effect of pharmacologically blocking inhibition might have been the consequence of blocking their inhibitory actions on granule cells. Two lines of evidence argue against this possibility. First, we found a high correlation between patches of granule cells that elicit inhibition and locations superficial to them in the molecular layer whose direct activation also inhibited the target Purkinje cell. This suggests that the changes in the Purkinje cell response maps after blocking inhibition are due specifically to blocking of inhibitory action of molecular layer interneurons to Purkinje cells. Second, in parallel preliminary experiments, we have directly tested the contribution of Golgi cell inhibition to Purkinje cell response patterns by granule cells. To do so, we took advantage of the fact that the bulk of inhibitory action of Golgi cells on granule cells is mediated by their tonic inhibition. This tonic inhibition is mediated by $\alpha 6$ subunit-containing GABA $_{\mathrm{A}}$ receptors (Rossi and Hamann, 1998; Hamann et al., 2002). $\alpha 6$ receptors are selectively blocked by furosemide, which blocks 
them with an $\mathrm{IC}_{50}$ of $10 \mu \mathrm{M}$, compared with an $\mathrm{IC}_{50}$ of $>3 \mathrm{~mm}$ for $\alpha 1$, the subunit expressed in Purkinje cells (Hamann et al., 2002). Blockade of $\alpha 6$ receptors with $100 \mu \mathrm{M}$ furosemide did not alter the maps, suggesting that Golgi cells make little contribution to the effects reported here when inhibition was blocked by picrotoxin.

Despite the prominent stereotypic contribution of molecular layer interneurons to functional properties of the cerebellar cortex, relatively little is known regarding their role in cerebellar function and motor coordination. On the basis of the anatomy, Szentagothai (1965) suggested that interneurons provide for lateral inhibition. Soon after, Eccles (1973) showed the reciprocal activity of two simultaneously recorded Purkinje cells separated by $660 \mu \mathrm{m}$ in the sagittal orientation, in response to the same cutaneous input in decerebrate cats. Since movement requires coordination of activity of opposing sets of agonist and antagonist muscles, one function of this lateral inhibition might be to allow for efficient generation of reciprocal signals from the same mossy fiber synaptic input. The role of feedforward inhibition in increasing the precision of excitation in Purkinje cells is clearly demonstrated in slice experiments (Brunel et al., 2004; Mittmann et al., 2005). Whether these roles of interneurons are cardinal for cerebellar function remains to be established. This is because in mice genetic ablation of inhibition to Purkinje cells does little to motor coordination save altering the ability of the animal to consolidate motor learning (Wulff et al., 2009). However, because transgenic mouse models are subject to developmental compensation, it will be invaluable to reaffirm these results in a conditional mouse in which inhibition is knocked out only in the adult animal after completion of cerebellar development. In fact, our own preliminary data suggest that acute pharmacological blockade of $\mathrm{GABA}_{\mathrm{A}}$ receptors in the cerebellar cortex results in severe ataxia and dyskinesia. Indeed, aberrant inhibitory signaling is implicated in several mouse models of ataxia, including episodic ataxia type 1 (Herson et al., 2003) and the P/Q-type calcium channel mutant leaner (Ovsepian and Friel, 2010).

The stereotypic maps of the connectivity and the contribution of interneurons in shaping the responses of Purkinje cells shown here need not suggest a static circuit. Plasticity at inhibitory synapses to Purkinje cells has been shown to modify the strength of inhibitory synaptic inputs from molecular layer interneurons to Purkinje cells (Mittmann and Häusser, 2007), and it will not be surprising if additional sites of plasticity involving interneurons are not identified in the future. Thus, alterations in the strength of inhibitory input to Purkinje cells by plasticity may alter the cerebellar circuitry and make a significant contribution to cerebellar motor learning.

\section{References}

Andersen P, Eccles JC, Voorhoeve PE (1964) Postsynaptic inhibition of cerebellar Purkinje cells. J Neurophysiol 27:1138-1153.

Bower JM (2010) Model-founded explorations of the roles of molecular layer inhibition in regulating Purkinje cell responses in cerebellar cortex: more trouble for the beam hypothesis. Front Cell Neurosci 4:pii:27.

Brunel N, Hakim V, Isope P, Nadal JP, Barbour B (2004) Optimal information storage and the distribution of synaptic weights: perceptron versus Purkinje cell. Neuron 43:745-757.

Chadderton P, Margrie TW, Häusser M (2004) Integration of quanta in cerebellar granule cells during sensory processing. Nature $428: 856-860$.

Cohen D, Yarom Y (1998) Patches of synchronized activity in the cerebellar cortex evoked by mossy-fiber stimulation: questioning the role of parallel fibers. Proc Natl Acad Sci U S A 95:15032-15036.
Cohen D, Yarom Y (2000a) Cerebellar on-beam and lateral inhibition: two functionally distinct circuits. J Neurophysiol 83:1932-1940.

Cohen D, Yarom Y (2000b) Unravelling cerebellar circuitry: an optical imaging study. Prog Brain Res 124:107-114.

Dieudonne S (1998) Submillisecond kinetics and low efficacy of parallel fibre Golgi cell synaptic currents in the rat cerebellum. J Physiol 510:845-866.

Eccles JC (1973) The cerebellum as a computer: patterns in space and time. J Physiol 229:1-32.

Eccles JC, Ito M, Szenthagothai J (1967) The cerebellum as a neuronal machine. Heidelberg: Springer.

Fino E, Araya R, Peterka DS, Salierno M, Etchenique R, Yuste R (2009) RuBi-glutamate: two-photon and visible-light photoactivation of neurons and dendritic spines. Front Neural Circuits 3:2.

Gao W, Chen G, Reinert KC, Ebner TJ (2006) Cerebellar cortical molecular layer inhibition is organized in parasagittal zones. J Neurosci 26:8377-8387.

Hamann M, Rossi DJ, Attwell D (2002) Tonic and spillover inhibition of granule cells control information flow through cerebellar cortex. Neuron 33:625-633.

Harvey RJ, Napper RM (1991) Quantitative studies on the mammalian cerebellum. Prog Neurobiol 36:437-463.

Häusser M, Clark BA (1997) Tonic synaptic inhibition modulates neuronal output pattern and spatiotemporal synaptic integration. Neuron 19:665-678.

Herson PS, Virk M, Rustay NR, Bond CT, Crabbe JC, Adelman JP, Maylie J (2003) A mouse model of episodic ataxia type-1. Nat Neurosci 6:378-383.

Ito M (1984) The cerebellum and neural control. New York: Raven Press.

Jaeger D, Bower JM (1994) Prolonged responses in rat cerebellar Purkinje cells following activation of the granule cell layer: an intracellular in vitro and in vivo investigation. Exp Brain Res 100:200-214.

Jörntell H, Ekerot CF (2006) Properties of somatosensory synaptic integration in cerebellar granule cells in vivo. J Neurosci 26:11786-11797.

Kanichay RT, Silver RA (2008) Synaptic and cellular properties of the feedforward inhibitory circuit within the input layer of the cerebellar cortex. J Neurosci 28:8955-8967.

Mittmann W, Häusser M (2007) Linking synaptic plasticity and spike output at excitatory and inhibitory synapses onto cerebellar Purkinje cells. J Neurosci 27:5559-5570.

Mittmann W, Koch U, Häusser M (2005) Feed-forward inhibition shapes the spike output of cerebellar Purkinje cells. J Physiol 563:369-378.

Napper RM, Harvey RJ (1988) Number of parallel fiber synapses on an individual Purkinje cell in the cerebellum of the rat. J Comp Neurol 274:168-177.

Ovsepian SV, Friel DD (2010) Enhanced synaptic inhibition disrupts the efferent code of cerebellar Purkinje neurons in leaner $\mathrm{Ca}_{\mathrm{v}} 2.1 \mathrm{Ca}^{2+}$ channel mutant mice. Cerebellum. Advance online publication. Retrieved June 16, 2011. doi:10.1007/s12311-010-0210-9.

Palay SL, Chan-Palay V (1974) Cerebellar cortex. Berlin: Springer.

Raman IM, Bean BP (1999) Ionic currents underlying spontaneous action potentials in isolated cerebellar Purkinje neurons. J Neurosci 19:1663-1674.

Rancz EA, Ishikawa T, Duguid I, Chadderton P, Mahon S, Häusser M (2007) High-fidelity transmission of sensory information by single cerebellar mossy fibre boutons. Nature 450:1245-1248.

Rossi DJ, Hamann M (1998) Spillover-mediated transmission at inhibitory synapses promoted by high affinity $\alpha_{6}$ subunit $\mathrm{GABA}_{\mathrm{A}}$ receptors and glomerular geometry. Neuron 20:783-795.

Santamaria F, Tripp PG, Bower JM (2007) Feedforward inhibition controls the spread of granule cell-induced Purkinje cell activity in the cerebellar cortex. J Neurophysiol 97:248-263.

Sullivan MR, Nimmerjahn A, Sarkisov DV, Helmchen F, Wang SS (2005) In vivo calcium imaging of circuit activity in cerebellar cortex. J Neurophysiol 94:1636-1644.

Sultan F (2001) Distribution of mossy fibre rosettes in the cerebellum of cat and mice: evidence for a parasagittal organization at the single fibre level. Eur J Neurosci 13:2123-2130.

Sultan F, Bower JM (1998) Quantitative Golgi study of the rat cerebellar molecular layer interneurons using principal component analysis. J Comp Neurol 393:353-373. 
Szentagothai J (1965) The use of degeneration methods in the investigation of short neuronal connexions. Prog Brain Res 14:1-32.

Thach WT (1968) Discharge of Purkinje and cerebellar nuclear neurons during rapidly alternating arm movements in the monkey. J Neurophysiol 31:785-797.

Thach WT (1970) Discharge of cerebellar neurons related to two maintained postures and two prompt movements. II. Purkinje cell output and input. J Neurophysiol 33:537-547.

Walter JT, Khodakhah K (2006) The linear computational algorithm of cerebellar Purkinje cells. J Neurosci 26:12861-12872.

Walter JT, Khodakhah K (2009) The advantages of linear information processing for cerebellar computation. Proc Natl Acad Sci U S A 106:4471-4476.
Walter JT, Dizon MJ, Khodakhah K (2009) The functional equivalence of ascending and parallel fiber inputs in cerebellar computation. J Neurosci 29:8462-8473.

Wulff P, Schonewille M, Renzi M, Viltono L, Sassoè-Pognetto M, Badura A, Gao Z, Hoebeek FE, van Dorp S, Wisden W, Farrant M, De Zeeuw CI (2009) Synaptic inhibition of Purkinje cells mediates consolidation of vestibulo-cerebellar motor learning. Nat Neurosci 12:10421049.

Zhang W, Linden DJ (2010) Calcium influx measured at single presynaptic boutons of cerebellar granule cell ascending axons and parallel fibers. Cerebellum. Advance online publication. Retrieved June 16, 2011. doi: 10.1007/s12311-009-0151-3 